\title{
USE OF ALTERNATIVE FUELS OBTAINED FROM RENEWABLE SOURCES IN BRAYTON CYCLES
}

\section{ESCUDERO \\ Á. JIMÉNEZ* \\ I. LÓPEZ \\ J. RODRÍGUEZ}

Received: 05/12/11

Accepted: 09/03/12

\author{
Department of Energy Engineering and Fluid Mechanics \\ ETSI Industriales, Universidad Politécnica de Madrid, Spain
}

\begin{abstract}
Analysis and simulation of the behaviour of gas turbines for power generation using different nonconventional fuels obtained from different renewable sources are presented. Three biomass-tobiofuel processes are considered: anaerobic digestion of biomass (biogas), biomass gasification (synthesis gas) and alcoholic fermentation of biomass and dehydration (bioethanol), each of them with two different biomass substrates (energy crops and municipal solid waste) as input.

The gas turbine behaviour in a Brayton cycle is simulated both in an isolated operation and in combined cycle. The differences in gas turbine performance when fired with the considered biofuels compared to natural gas are studied from different points of view related with the current complex energetic context: energetic and exergetic efficiency of the simple/combined cycle and $\mathrm{CO}_{2}$ emissions. Two different tools have been used for the simulations, each one with a different approach: while PATITUG (own software) analyses the behaviour of a generic gas turbine allowing a total variability of parameters, GT-PRO (commercial software) is more rigid, albeit more precise in the prediction of real gas turbine behaviour. Different potentially interesting configurations and its thermodynamic parameters have been simulated in order to obtain the optimal range for all of them and its variation for each fuel.
\end{abstract}

KEYWORDS: renewable energy sources, bioenergy, biofuels for power generation, gas turbine systems, Brayton combined cycle, emissions reduction

\section{OBJETIVE AND INTRODUCTION}

The goal of this work is to simulate and analyse the behaviour of gas turbines for power generation using different non-conventional fuels (biogas, synthesis gas and bioethanol) obtained from different biomass renewable resources energy crops (EC) and municipal solid waste (MSW).

Gas turbine power generation is being pushed to the utilisation of alternative fuels that can be used with reliability and efficiency (Basu et al., 2001; Gökalp and Lebas, 2004; Gadde et al., 2006; Shortt, 2005; Nieto et al., 2011). Different reasons arise behind this new tendency, e.g. price evolution of natural gas and availability of renewable sources (McMillan et al., 2006), environmental strategies (Board, 2005) and pollutant emissions (Anheden, 2000; Rising et al., 2004) among others. In the last years, the energy policies of the industrialized countries have been encouraging to find more sustainable ways of power generation. Nevertheless, many of the signatories of the Kioto protocol are not reaching the greenhouse gas emission objective for 2012. Anyway, more ambitious limits should be set in the future, and therefore, further research on the use of $\mathrm{CO}_{2}$-free alternative fuels is highly needed and will be promoted.

In this context, combustion of biomass and biofuels as an alternative to conventional fuels is becoming and active area of research in the recent years: Elmegaard et al., 2003; IDAE, 2007; Hilkiah-Igoni, 2008; Dong, 2010; San Miguel et al., 2010; Al-attab and Zainal, 2010, as an example. In this works, external combustion of biomass or co-combustion with coal, external combustion of 
biofuels, and the use of biofuels in internal combustion engines technologies are examined. Gas turbines allow the operation in higher ranges of power and obtain significantly higher energetic and exergetic efficiencies if they are configured in combination with a steam cycle (combined cycle, CC). With the same goal, the Integrated Gasification Combined Cycle (IGCC) power plants represent a mature technology for high efficient power generation from coal.

In this paper, the behaviour of gas turbines working with different biofuels, namely biogas, synthesis gas (syngas) and bioethanol will be analysed. Natural gas is taken as the reference fuel since it is the most commonly used fuel in gas turbine power generation installations. For the set of considered biofuels, the differences in performance with the reference case are studied from different points of view in relation with the complex current energetic context, mainly:

- energetic and exergetic efficiency of the simple/combined cycle

- $\mathrm{CO}_{2}$ emissions.

Different potentially interesting configurations and its thermodynamic parameters have been simulated in order to obtain its optimal values for all of them and its variation for each fuel. This optimisation has been performed with a very precise and rigorous thermodynamic modelling, regarding thermal state equations, mixing models, properties calculation, etc., through the use of PATITUG, a modular and flexible software tool for design, analysis and optimisation of thermodynamic cycles developed by the Applied Thermodynamics Group of the Universidad Politécnica de Madrid. It allows a total and completely free variability of the main design parameters, and full control of the physical models applied. PATITUG provides a series of different modules that calculate thermodynamic properties of the streams that take part in the cycle and the behaviour of the components involved from a thermodynamic point of view. Modules have been implemented for filters, mixing chambers, adiabatic humidifiers, pumps, compressors, adiabatic turbines, refrigerated turbines, combustion chambers, heat recovering boilers and heat exchangers, among others. Models for handling substances, mixtures and chemical reactions are included. A variety of state equations, like ideal gas, virial gas, Lee-Kesler state equation and the IAPWS-IF97 equation for water, as well as different expressions for the heat capacity at null pressure limit, can be selected. For mixtures, the models of ideal gas mixture and Lewis-Randall mixture are available. Other recent studies have been carried with this software (Nieto et al., 2011).

Once the optimal configurations and cycle parameters have been defined, calculations for the power plant have been carried out, considering the commercial turbines and devices that are more adequate for the optimised conditions obtained in the previous phase. For this purpose, GT-PRO (Thermoflow Inc., 2001) has been used. GT-PRO is a commercial application software that includes data about a huge set of industrial gas turbines; it is more rigid, albeit more precise in the prediction of the particular gas turbines behaviour.

\section{METHODS}

A thorough bibliographical research was carried out to collect the data needed for the study, mostly concerning typical chemical composition values for biogas (Rao and Singh, 2003), (Deublein and Steinhauser, 2008); syngas (Mueller-Langer et al., 2007; Wang et al., 2009) and bioethanol (Kim and Dale, 2004; Pimentel and Patzek, 2005; Kwiatkowski et al., 2006; Sassner et al., 2008).

\subsection{PATITUG simulations}

A standard gas turbine has been programmed with PATITUG as shown in Figure 1. Thermodynamic properties in PATITUG have been calculated using the two-term virial equation of state for air components and the Lee-Kesler generalised equation (Lee and Kessler, 1975) for the fuels. All gas mixtures have been treated as ideal (Lewis-Randall). For all components, the correlation of exponential type given in (Daubert and Danner, 1989) is used for the specific heat at null pressure. 


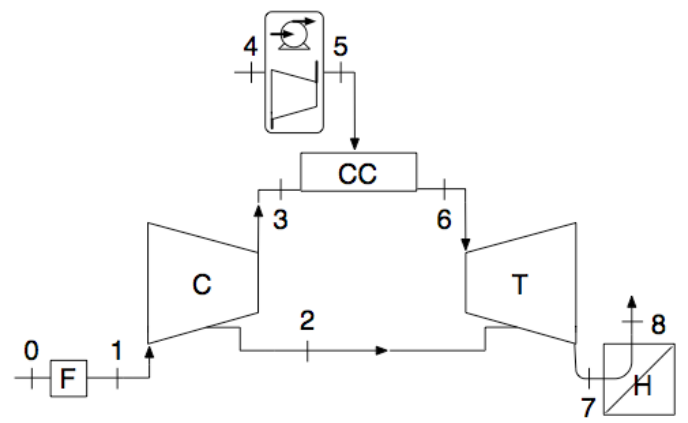

$$
\begin{aligned}
& T_{0}=15^{\circ} \mathrm{C}, P_{0}=1 \mathrm{bar} \\
& \Delta P_{\mathrm{F}}=P_{0}-P_{1}=996.3 \mathrm{~Pa} \\
& \eta_{s, \mathrm{C}}=0.845 \\
& m_{2}=0.062 m_{1} \\
& T_{4}=15^{\circ} \mathrm{C}, P_{4}=10.34 \mathrm{bar} \\
& P_{5}=1.41 P_{3}\left(\eta_{s, 4-5}=0.84\right) \\
& \Delta P_{\mathrm{CC}}=P_{3}-P_{6}=0.0399 P_{3}, Q_{\mathrm{CC}}=0.0034 e_{4} \\
& \eta_{s, \mathrm{~T}}=0.845 \\
& P_{7}=1.2499 \text { bar } \\
& T_{8}=120^{\circ} \mathrm{C}
\end{aligned}
$$

Figure 1. Schematic view of the programmed Combined Cycle and its parameters

The programme calculates the exergetic efficiencies in simple and combined cycle:

$$
\begin{aligned}
& \xi_{\mathrm{SC}}=\frac{\eta_{\mathrm{em}}\left(W_{\mathrm{T}}+W_{\mathrm{C}}+W_{4-5}\right)}{m_{4} e_{4}} \\
& \xi_{\mathrm{CC}}=\frac{\eta_{\mathrm{em}}\left(W_{\mathrm{T}}+W_{\mathrm{C}}+W_{\mathrm{F}}\right)+\zeta m_{7}\left(e_{7}-e_{8}\right)}{m_{4} e_{4}}
\end{aligned}
$$

with $W_{T}$ the turbine gross power output, $W_{C}$ and $W_{4-5}$ the turbine compressor and the fuel compressor/pump gross power consumptions. $e_{i}$ is the chemical flow exergy of stream $i$. A global electromechanical conversion efficiency $\eta_{\mathrm{em}}$ is introduced and assumed equal to 0.98 . The fraction of the combustion gases exergy recovered in the HRSG and converted into work by the steam cycle $\zeta$ have been assumed equal to 0.7 .

The maximum efficiency conditions were found for each of the studied fuels, in both simple and combined cycle. Furthermore, the variation of efficiency related to turbine inlet temperature (TIT) and compressor pressure ratio (PR) was analysed and exergy balances were performed. TIT was limited between 1273.15-1723.15 K while limits for PR were 10 and 40. The lower limits were chosen considering that the efficiency at lower inlet temperatures or pressure ratios would be uninteresting, while the upper limits were set considering that gas turbines will not usually be capable to work above them.

Natural gas was considered as pure methane. Biogas was considered as a mixture of mainly methane and carbon dioxide, with small constant quantities of oxygen and nitrogen $\left(x_{\mathrm{N}_{2}}=0.04\right.$ and $x_{\mathrm{O}_{2}}=0.01$ ), typical in biogas (Deublein and Steinhauser, 2008). $x_{\mathrm{CH}_{4}}$ was varied from 0.45 to 0.75 (and hence $x_{\mathrm{CO}_{2}}$ from 0.5 to 0.2 ), covering the whole range of typical biogas compositions, as calculated using data from different energy crops biomass compositions (Duke, 1983) and empirically confirmed for some of them (Amon et al., 2003). Syngas was studied as a binary $\mathrm{H}_{2}-\mathrm{CO}$ mixture and then the influence of adding $\mathrm{CO}_{2}$ up to $30 \%$ was studied in a $x_{\mathrm{H}_{2}} / x_{\mathrm{CO}}=1$ case.

\subsection{GT-PRO simulations}

After completing the analysis of the results yielded by the previous of simulations, a further study with GT-PRO was started. Now a real natural gas (containing impurities) was considered as reference. The composition of this fuel is: $97.65 \% \mathrm{CH}_{4}, 0.97 \% \mathrm{C}_{2} \mathrm{H}_{6}, 0.3 \% \mathrm{C}_{3} \mathrm{H}_{8}, 0.11 \% \mathrm{C}_{4} \mathrm{H}_{10}$, $0.02 \% \mathrm{C}_{5} \mathrm{H}_{12}, 0.01 \% \mathrm{C}_{6} \mathrm{H}_{14} 0.86 \% \mathrm{~N}_{2}, 0.08 \% \mathrm{CO}_{2}$.

Regarding biogas from energy crops, a composition of $53 \% \mathrm{CH}_{4}$, a methane generation of $180 \mathrm{Nm}^{3} \mathrm{t}^{-1}$ of substrate (maize) and a $24 \mathrm{kWh} \mathrm{t}^{-1}$ electric and $240 \mathrm{kWh} \mathrm{t}^{-1}$ heat consumption have been considered (Deublein and Steinhauser, 2008). If the substrate is MSW, the biogas methane content is $65 \%$ and the yield is $200 \mathrm{Nm}^{3} \mathrm{CH}_{4} \mathrm{t}^{-1}$, with a power and heat consumption of 18.7 and $2.25 \mathrm{kWh} \mathrm{t}^{-1}$ (Rao and Singh, 2003). This has been taken into account in the GT-PRO simulations.

GT-PRO allows the simulation of a gasification plant obtaining syngas fuel from biomass, with the possibility of adding a pre-combustion $\mathrm{CO}_{2}$ capture module. It calculates the final syngas composition and the energy consumption in these processes. A Texaco gasifier with radiant and 
convective coolers has been chosen for the simulation. Ambient air ( $288.15 \mathrm{~K}, 1 \mathrm{bar}$ ) is compressed to the air separation unit (ASU) working conditions (288.15 K, 5.171 bar).

For ethanol an energy consumption of $20 \%$ has been considered, based on an average value of the results of previous studies (Pimentel and Patzek, 2005; Sassner et al., 2008). It should be pointed out that some of the found data on energy consumption for ethanol production do not always agree.

Using data from the GT-PRO simulation, $\mathrm{CO}_{2}$ emission intensities were calculated. However, some problems were encountered when evaluating net emissions for biofuels, as the complete carbon cycle must be considered, i.e. the carbon that is fixed from the atmosphere by biomass during its growth as well as the power plant emission. No clear data about how to calculate $\mathrm{CO}_{2}$ net emission using biofuels were found, and, as a matter of fact, European Environment Agency (EEA) studies reveal that there is a high variability in net emission values (and these can be either positive or negative) and depend on the substrate and the technology used to obtain the biofuel (EEA, 2008).

example of the kind of problems encountered when trying to find a single indicator to quantify the net emission of a power plant which uses biofuels, if the emission intensity $F$ is calculated as $F=\left(E_{+}-\right.$ $\left.E_{-}\right) / P$, being $E_{+}$the power plant emission, $E_{-}$the carbon which is fixed by the biomass and $P$ the net power output, it would be concluded that:

- a less efficient biomass-to-fuel conversion process (i.e. which needs more biomass to produce the same amount of fuel) would be environmentally more advantageous ( $F$ becomes smaller).

- if $F<0$ a less efficient power plant would be environmentally better ( $|F|$ would increase).

These conclusions would be misleading so the previous approach was rejected.

Furthermore, not all of the carbon in the biomass ends up in the fuel, and the fraction of carbon that does so is different for each fuel and substrate, e.g. while in gasification approximately $98 \%$ of the initial carbon gets to the fuel, in anaerobic digestion this value is around $36 \%$ using energy crops as a substrate. Therefore, the net emission will depend on the final destination of the residual carbon (solid or as $\mathrm{CO}_{2}$ in alcoholic fermentation).

Taking into account the aforementioned issues, net $\mathrm{CO}_{2}$ emissions for all biofuels were considered equal to zero, as is advised by the Spanish Ministry of Industry in its Renewable Energy Plan for 2005-2010 (MITC and IDAE, 2005). For MSW, the value set in the same document will be used: $60.5 \mathrm{tCO}_{2}$ per $\mathrm{GW}_{\text {th }} \mathrm{h}$. If there is pre-combustion $\mathrm{CO}_{2}$ capture, then the net emission would be the result of subtracting the gross power plant emission with capture to that obtained with gasification without capture. The efficiency of $\mathrm{CO}$ shift reaction and $\mathrm{CO}_{2}$ capture were assumed equal to $98 \%$ and $90 \%$ respectively.

\section{RESULTS AND DISCUSSION}

\subsection{Analysis using PATITUG}

Tables 1 to 4 show the conditions (TIT and PR) for which the exergetic efficiency of the modelled gas turbine is maximum for simple and combined cycle when working with methane, biogas (with constant $x_{\mathrm{N}_{2}}=0.04$ and $x_{\mathrm{N}_{2}}=0.01$ ), syngas (binary $\mathrm{H}_{2}-\mathrm{CO}$ ) and ethanol, respectively.

Table 1. Maximum exergetic efficiency conditions for pure methane

\begin{tabular}{cccccc}
\hline$\xi_{\mathrm{SC}, \max }$ & TIT $(\mathrm{K})$ & $\mathrm{PR}$ & $\xi_{\mathrm{CC}, \max }$ & TIT $(\mathrm{K})$ & $\mathrm{PR}$ \\
\hline 0.3506 & 1723.15 & 40 & 0.5411 & 1723.15 & 29.5 \\
\hline
\end{tabular}

The dependence of the exergetic efficiency with the fuel composition is presented in Figures 2 and 3 . Figure 2 shows the curves of the exergetic efficiency in simple and combined cycle respectively, as a function of pressure ratio, for a binary biogas $\left(\mathrm{CH}_{4}-\mathrm{CO}_{2}\right)$ in the case of TIT $=1723.15 \mathrm{~K}$, when varying the $\mathrm{CH}_{4}$ fraction. Figure 3 shows analogous results for a $x_{\mathrm{H}_{2}} / x_{\mathrm{CO}}=1$ syngas with varying $\mathrm{CO}_{2}$ fractions. 
Table 2. Maximum exergetic efficiency conditions for biogas

\begin{tabular}{ccccccc}
\hline$x_{\mathrm{CH} 4}$ & $\xi_{\mathrm{SC}, \max }$ & TIT $(\mathrm{K})$ & PR & $\xi_{\mathrm{CC}, \max }$ & TIT (K) & PR \\
\hline 0.45 & 0.3476 & 1723.15 & 40 & 0.5316 & 1723.15 & 32.7 \\
\hline 0.55 & 0.3491 & 1723.15 & 40 & 0.5353 & 1723.15 & 31.5 \\
\hline 0.65 & 0.3501 & 1723.15 & 40 & 0.5378 & 1723.15 & 30.8 \\
\hline 0.75 & 0.3507 & 1723.15 & 40 & 0.5396 & 1723.15 & 30.2 \\
\hline
\end{tabular}

Table 3. Maximum exergetic efficiency conditions for syngas

\begin{tabular}{ccccccc}
\hline $\mathrm{X}_{\mathrm{H} 2}$ & $\xi_{\text {sC,max }}$ & TIT $(\mathrm{K})$ & $\mathrm{PR}$ & $\xi_{\mathrm{CC}, \max }$ & TIT $(\mathrm{K})$ & $\mathrm{PR}$ \\
\hline 0.40 & 0.3608 & 1723.15 & 38.5 & 0.5670 & 1723.15 & 21.5 \\
\hline 0.50 & 0.3602 & 1723.15 & 38.0 & 0.5654 & 1723.15 & 21.5 \\
\hline 0.60 & 0.3594 & 1723.15 & 37.5 & 0.5634 & 1723.15 & 21.5 \\
\hline 0.70 & 0.3585 & 1723.15 & 37.5 & 0.5612 & 1723.15 & 21.5 \\
\hline 0.80 & 0.3573 & 1723.15 & 37.5 & 0.5586 & 1723.15 & 22.0 \\
\hline 0.90 & 0.3558 & 1723.15 & 37.0 & 0.5555 & 1723.15 & 22.0 \\
\hline 1.00 & 0.3537 & 1723.15 & 37.0 & 0.5514 & 1723.15 & 22.0 \\
\hline
\end{tabular}

Table 4. Maximum exergetic efficiency conditions for pure ethanol

\begin{tabular}{cccccc}
\hline$\xi_{\text {SC, } \max }$ & TIT $(\mathrm{K})$ & PR & $\xi_{\text {CC, } \max }$ & TIT $(\mathrm{K})$ & PR \\
\hline 0.3399 & 1723.15 & 40 & 0.5177 & 1723.15 & 35.75
\end{tabular}
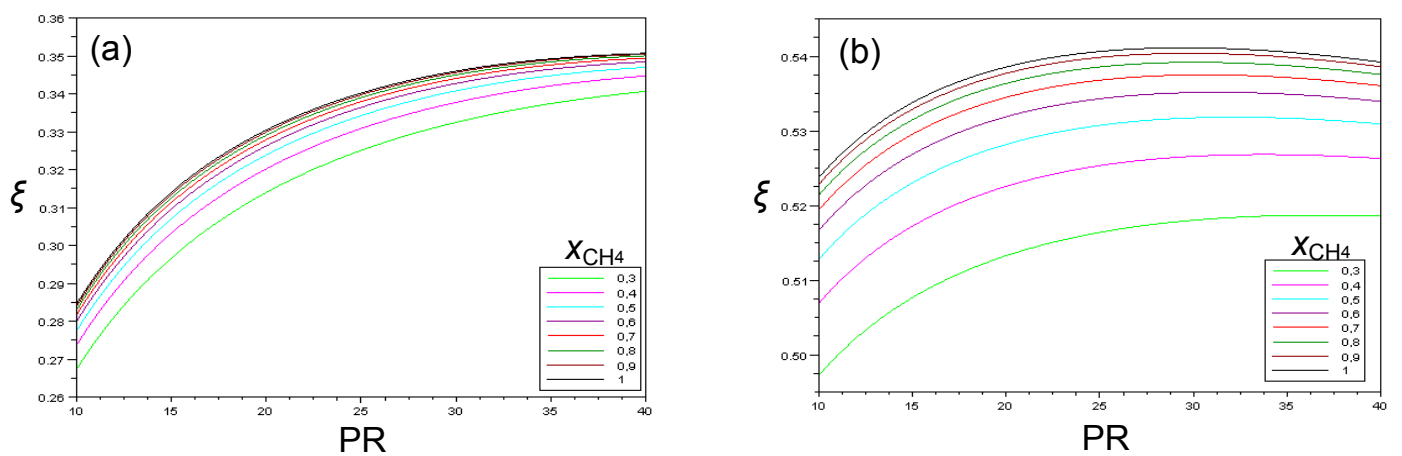

Figure 2. Dependence of exergetic efficiency as a function of PR on biogas composition (a) simple cycle; (b) combined cycle
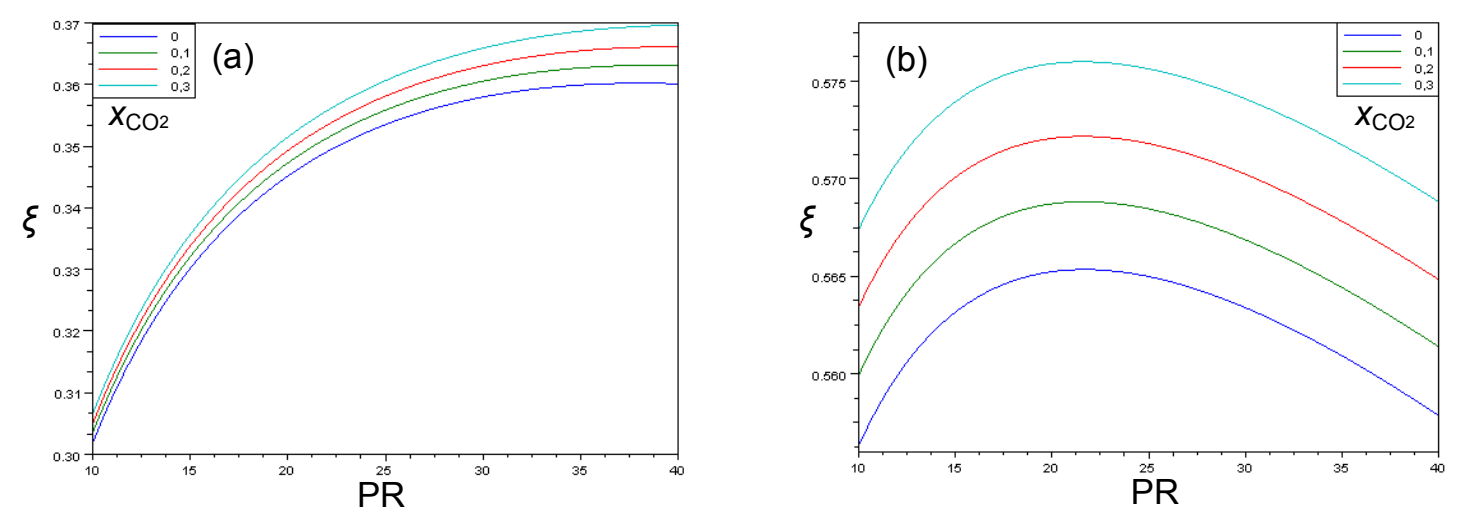

Figure 3. Dependence of exergetic efficiency as a function of PR on syngas composition. (a) simple cycle; (b) combined cycle

The exergy balances in the gas turbine also provide interesting information. Figure 4 shows these balances, for the maximum TIT and for the whole range of PR considered, for pure methane, biogas $\left(53 \% \mathrm{CH}_{4}, 42 \% \mathrm{CO}_{2}, 4 \% \mathrm{~N}_{2}, 1 \% \mathrm{O}_{2}\right)$, syngas (50\% $\mathrm{H}_{2}, 50 \% \mathrm{CO}$ ) and pure ethanol, respectively. 
It can be noticed that the exergy destruction obtained with syngas is the lowest, and the exergy carried by the combustion gases is higher for this fuel than for natural gas, what opens the door to a better heat recovery efficiency in the HRSG if a combined cycle were planned. Ethanol presents the highest exergy destruction.
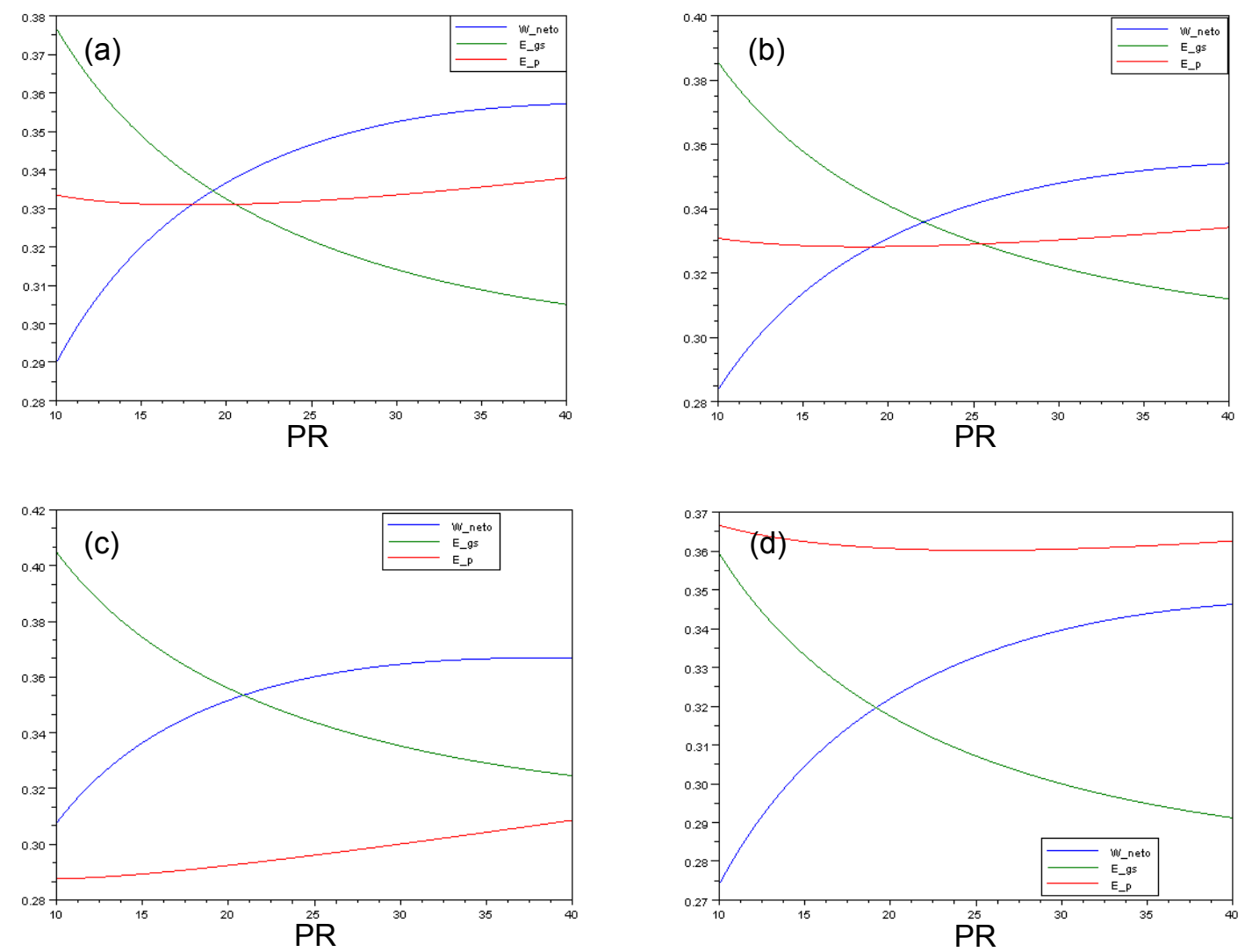

Figure 4. Exergy balances in the gas turbine as a function of PR for TIT $=1723.15 \mathrm{~K}$. Net turbine power output in blue; exhaust gases exergy in green; exergy destruction in red. All values are expressed as a fraction of the inlet exergy $\left(m_{4} e_{4}\right)$. (a) methane; (b) biogas; (c) syngas; (d) ethanol

\subsection{Analysis using GT-PRO}

Gas turbine maximum gross LHV efficiencies found in the simulations with GT-PRO using two different commercial gas turbines for the fuels under study are shown in Table 5. Two different size turbines have been chosen in order to highlight the possible scale effects.

Table 5. Efficiency of simple Brayton cycle for large and small size commercial gas turbines and its optima working conditions

\begin{tabular}{|c|c|c|c|c|c|c|}
\hline \multirow[t]{2}{*}{ Fuel } & \multicolumn{3}{|c|}{$\begin{array}{l}\text { Mitsubishi 701-G } \\
\text { (334 MWe) }\end{array}$} & \multicolumn{3}{|c|}{$\begin{array}{c}\text { Siemens SGT-200-1S } \\
(6.7 \mathrm{MWe})\end{array}$} \\
\hline & $\xi_{\mathrm{sc}, \max }$ & TIT (K) & PR & $\xi_{\mathrm{sc}, \max }$ & TIT (K) & PR \\
\hline Natural gas & 0.3929 & 1700 & 21.0 & 0.3142 & 1297 & 11.8 \\
\hline Biogas from EC $\left(53 \% \mathrm{CH}_{4}\right)$ & 0.3994 & 1674 & 21.9 & 0.3182 & 1287 & 12.1 \\
\hline Biogas from MSW $\left(65 \% \mathrm{CH}_{4}\right)$ & 0.3978 & 1684 & 21.6 & 0.3152 & 1291 & 12.0 \\
\hline Syngas $\left(31 \% \mathrm{H}_{2}, 37 \% \mathrm{CO}\right)^{\mathrm{a}}$ & 0.4172 & 1653 & 21.9 & 0.3314 & 1278 & 11.9 \\
\hline Syngas $\left(87 \% \mathrm{H}_{2}, 1 \% \mathrm{CO}\right)^{\mathrm{a}, \mathrm{b}}$ & 0.4203 & 1704 & 20.5 & 0.3319 & 1297 & 11.4 \\
\hline Ethanol & 0.3919 & 1690 & 21.3 & 0.3152 & 1295 & 11.9 \\
\hline
\end{tabular}

Now the optima conditions are slightly different than the predicted by PATITUG for each of the fuels, due to effects other than those purely thermodynamical (mainly related to the specific turbine design) 
which were not taken into account with PATITUG, and to the different definition of the efficiency (LHV and $e$ are very close for all fuels, but they are no exactly the same). The smaller turbine has lower efficiencies because both its turbine inlet temperature and pressure ratio are lower. Results for differences in exergy loss between fuels found with PATITUG are confirmed by GT-PRO.

Considering the complete biomass-to-power process through a gas turbine system, two main steps occur: the biomass-to-biofuel process (here anaerobic digestion, gasification and fermentationdehydration have been considered) and the power production by the gas turbine fired by that biofuel (biogas, syngas and bioethanol, respectively). The results of simulation of the second step have been showed in Table 5. For the overall biomass-to-power cycle, taking into account the auxiliary power consumption in the first step, gasification yields a higher efficiency than biogas and bioethanol production, especially in combined cycle. This is due to a higher biomass-to-fuel conversion efficiency and to the recirculation of the water vapour produced in the gasification process to the HRSG in combined cycle, which allows an extra power production in the Rankine cycle. The greatest auxiliary power comsumption takes place in the case of gasification. In a biomass IGCC with precombustion $\mathrm{CO}_{2}$ capture, $60-65 \%$ of the auxiliary power consumption would be due to the gasifier ( $85 \%$ of it to the ASU), and $31-36 \%$ to $\mathrm{CO}_{2}$ capture. The actual values depend on the substrate. The decrease of efficiency when adding pre-combustion $\mathrm{CO}_{2}$ capture is around $6 \%$ in combined cycle and $4-6 \%$ in simple cycle. Net feedstock (biomass or natural gas) LHV efficiencies are shown for simple and combined cycles in Table 6 for the Mitsubishi 701-G turbine. Calculated gas turbine optimum conditions are the same for both simple and combined cycles.

Table 6. Overall biomass-to-power efficiency of the simple and combined cycle

\begin{tabular}{lll}
\hline Fuel & Simple & Combined \\
\hline Natural gas & 0.3833 & 0.5410 \\
\hline Biogas from $\mathrm{EC}$ biomass $\left(53 \% \mathrm{CH}_{4}\right)$ & 0.1383 & 0.1804 \\
\hline Biogas from $\mathrm{MSW}\left(65 \% \mathrm{CH}_{4}\right)$ & 0.2210 & 0.3124 \\
\hline Syngas from $\mathrm{EC}$ biomass & 0.2050 & 0.4152 \\
\hline Syngas from $\mathrm{EC}$ biomass with $\mathrm{CO}_{2}$ capture & 0.1575 & 0.3398 \\
\hline Syngas from $\mathrm{MSW}$ & 0.1834 & 0.3779 \\
\hline Syngas from $\mathrm{MSW}$ with $\mathrm{CO}_{2}$ capture & 0.1357 & 0.3294 \\
\hline Ethanol & 0.1348 & 0.2036 \\
\hline
\end{tabular}

\subsection{Carbon dioxide emissions}

Simulations were carried out on three large-size gas turbines in combined cycle to calculate the emission using natural gas and those saved with $\mathrm{CO}_{2}$ capture: Ansaldo $\mathrm{AE}$

94.3A (284.8 MW), Siemens SGT5-4000F (263.6 MW) and Mitsubishi $701 \mathrm{G}$ (334 MW). The mean value of emission intensity in natural gas combined cycle (NGCC) for the three turbines that were simulated is $369.5 \mathrm{tCO}_{2} \mathrm{GWh}^{-1}$. This would equal the emissions saved when using an energy-cropsbiofuel power plant without capture. Thus, the hypothetical substitution of a 400 MW NGCC working with capacity factor of $80 \%$, i.e. $2805 \mathrm{GWh}_{\text {year }}{ }^{-1}$ by an analogous CC power plant fired with that biofuel would save $1.04 \mathrm{MtCO}_{2}$ /yearr. If a precombustion $\mathrm{CO}_{2}$ capture module is added, the net carbon emission would be reduced further, reaching negative values (globally $\mathrm{CO}_{2}$ wolud be removed from the atmosphere). Assuming the CO oxidation efficiency of $98 \%$ and the capture module efficiency of $90 \%$, as stated previously, a total of $3.36 \mathrm{MtCO}_{2} /$ year would be avoided.

Table 7. Average $\mathrm{CO}_{2}$ emission intensities of $\mathrm{CC}$ fed by $\mathrm{EC}$ biomass and $\mathrm{MSW}$ and $\mathrm{CO}_{2}$ emissions saved when substituting a 400MW NGCC by a biomass CC of the same power output and capacity

\begin{tabular}{|l|c|c|c|}
\multicolumn{4}{c|}{ factor of $80 \%$} \\
\cline { 2 - 4 } \multicolumn{1}{c|}{} & \multicolumn{2}{c|}{$\mathrm{MSW}$} & $\mathrm{EC}$ \\
\cline { 2 - 4 } \multicolumn{1}{c|}{} & $\mathrm{tCO}_{2} \mathrm{GWh}^{-1}$ & $\mathrm{MtCO}_{2}$ saved & $\mathrm{MtCO}_{2}$ saved \\
\hline Anaerobic digestion (Biogas) & 194 & 0.46 & 1.04 \\
\hline Gasification (Syngas) & 158 & 0.56 & 1.04 \\
\hline Gasification (Syngas) $+\mathrm{CO}_{2}$ Capture & -654 & 2.83 & 3.36 \\
\hline Fermentation + dehydration (Ethanol) & - & - & 1.04 \\
\hline
\end{tabular}


For the case of MSW, a net emission of $60.5 \mathrm{t} \mathrm{CO}_{2} \mathrm{GW}_{\mathrm{th}}{ }^{-1}$ is considered. Hence, the global emission is related to the overall efficiency of the power plant. Table 7 shows the mean emission intensities for MSW Combined Cycles, and the $\mathrm{CO}_{2}$ emissions saved if a $400 \mathrm{MW}$ NGCC were substituted by an equivalent MSWCC with a capacity factor of $80 \%$ :

\section{CONCLUSIONS}

The thermodynamical cycle efficiency is high enough for all biofuels so that they can be thought of as an alternative to natural gas, being ethanol the worst from this point of view $(1 \%$ lower exergetic efficiency in simple Brayton cycle and $2.3 \%$ in combined cycle than natural gas). Syngas is the fuel which provides the highest efficiency (including methane) and it is reached at lower pressure ratios (21.5-22 for a combined cycle), more easily achievable by real gas turbines. Exergy destruction is also lower for syngas than for natural gas, so more exergy can be recovered from the exhaust gases, whereas the fuel with the highest exergy destruction is ethanol.

Considering the global conversion process of feedstock to electricity, gasification yields the highest efficiency, due to a higher efficiency in both the power generation and biomass-to-fuel processes. This is even more noticeable in combined cycle because the water vapour produced in the gasification process can be recirculated to the HRSG, so that a bigger fraction of the energy contained in the substrate is used in the power plant. Thus, an efficiency of around $40 \%$ in a biomass IGCC can be attained, much higher than that of biogas and ethanol plants $(\approx 20 \%)$, albeit around $14 \%$ lower than the obtained in NGCC. Pre-combustion $\mathrm{CO}_{2}$ capture in gasification plants requires an additional power consumption that means a $6 \%$ efficiency loss in combined cycle.

The $\mathrm{CO}_{2}$ emission reduction when using biofuels is important but difficult to measure. Around 370 $\mathrm{tCO}_{2} \mathrm{GWh}^{-1}$ can be saved by substituting a natural gas combined cycle for a power plant fired with biofuels produced from energy crops, with an additional $850-900 \mathrm{tCO}_{2} \mathrm{GWh}^{-1}$ if pre-combustion $\mathrm{CO}_{2}$ capture is used. This results in a $1 \mathrm{MtCO}_{2}$ reduction for a $400 \mathrm{MW}$ plant (3.36 $\mathrm{MtCO}_{2}$ with capture). These values are lower for MSW derived biofuels, as less carbon is fixed by the substrate. However, these figures should be revised via a thorough study of the carbon cycle for each case.

\section{REFERENCES}

Al-attab K.A. and Zainal Z.A., (2010) Performance of high-temperature heat exchangers in biomass fuel powered externally fired gas turbine systems, Renewable Energy, 35, 913-920.

Anheden M., (2000) Analysis of Gas Turbine Systems for Sustainable Energy Conversion. PhD Thesis, Department of Chemical Eng. and Technology. KTH, Stockholm, Sweden.

Basu A., Gradassi M., Sills R., Fleisch T. and Puri R. (2001) Use of dme as a gas turbine fuel. Proceedings from ASME Turbo Expo GT 2001. June 4-7 New Orleans, LA, USA.

Board C.A.R., (2005) Summary of the joint workshop on natural gas quality standards. Report CEC-6002005-012, CEC-04-IEP-01 CPUC R.04-01-025, California Department of Conservation. Division of Oil, Gas and Geothermal Resources.

Daubert T.E. and Danner R.P., (1989) Physical and Thermodynamic Properties of Pure Chemicals: Data Compilation. Hemisphere Publishing Corporation, New York.

Deublein D. and Steinhauser A., (2008) Biogas from Waste and Renewable Resources: An Introduction. Wiley-VCH. ISBN 978-3-527-31841-4.

Dong C., Yang Y., Yang R. and Zhang J., (2010) Numerical modeling of the gasification based biomass co-firing in a $600 \mathrm{MW}$ pulverized coal boiler, Applied Energy 87 2834-2838.

Duke J.A. (1983). Handbook of energy crops. Unpublished. Available from: <http://www.hotr.pur due.edu/duke_energy/pongamia_pinnata.htm>.

EEA (2008) Energy and environmnent report 2008. Report, European Environment Agency.

Elmegaard B., Henriksen U. and Qvale B., (2003) Thermodynamic analysis of supplementary-fired gas turbine cycles, International Journal of Applied Thermodynamics. 6(2), 85-92.

Gadde S., Wu J., Gulati A., McQuiggan G., Koestlin B. and Prade B., (2006) Syngas capable combustion systems development for advanced gas turbines. Proceedings from the ASME Turbo Expo 2006, Power for Land, Sea and Air. May 8-11 Barcelona, Spain.

Gökalp I. and Lebas E., (2004) Alternative fuels for industrial gas turbines, Applied Thermal Engineering, 24, 1655-1663.

Hilkiah-Igoni A, Ayotamuno M.J, Eze C.L, Ogaji S.O.T and Probert S.D., (2008) Designs of anaerobic digesters for producing biogas from municipal solid-waste, Applied Energy, 85 430-438. 
IDAE (2007). Biomasa: digestores anaerobios. Energías renovables: Energía de la Biomasa.

Kim S. and Dale B.E., (2004) Global potential bioethanol production from wasted crops and crop residues, Biomass and Bioenergy, 26, 361-375.

Kwiatkowski J.R. McAloon A.J., Taylor F. and Johnston D.B., (2006) Modeling the process and costs of fuel ethanol production by the corn dry-grind process, Industrial crops and products, 23, 288-296.

Lee B.I. and Kessler M.G., (1975) A generalized thermodynamic correlation based on three-parameter corresponding states, AIChE, 21, 510-527.

McMillan R. Martin P., Noden R. and Welch M., (2006) Gas fuel flexibility in a dry low emissions combustion system. Report, Siemens. Demag Delaval Industrial Turbomachinery Ltd., UK.

MITC and IDAE (2005) Plan de Energías Renovables para España 2005-2010.

Mueller-Langer F. Tzimas E., Kaltschmitt M. and Peteves S., (2007) Techno-economic assessment of hydrogen production processes for the hydrogen economy for the short and medium term, International Journal of Hydrogen Energy, 32, 3797-3810.

Nieto R. González C. López I. and Jiménez Á., (2011) Efficiency of a Standard Gas-Turbine Power Generation Cycle Running on Different Fuels, International Journal of Exergy, 9(1), 112-126.

Pimentel D. and Patzek T.W., (2005) Ethanol production using corn, switchgrass and wood; biodiesel production using soybean and sunflower, Natural Resources Research, 14, 65-76.

Rao M.S. and Singh S.P., (2003) Bioenergy conversion studies of organic fraction of MSW: kinetic studies and gas yield-organic loading relationships for process optimisation, Bioresource Technology, 95, 173-185.

Rising B., Wu J. and Sorurbakhsh P., (2004) Survey of ultratrace metals in gas turbine fuels. Proceedings from the 11th Annual International Petroleum Environmental Conference. October 12-15 2004 Albuquerque, NM, USA.

San Miguel G., Servert J. and Canoira L., (2010) Analysis of the evolution in biomass to energy strategies and regulations in Spain, Global NEST Journal, 12(4), 374-383.

Sassner P., Galbe M. and Zacchi G., (2008) Techno-economic evaluation of bioethanol production from three different lignocellulosic materials, Biomass and Bioenergy, 32, 422-430.

Shortt A.A., (2005) The use of di-methyl ether as alternative fuel in gas turbines for power generation. Report, Bateman Power and Energy.

Thermoflow Inc. (2001) GTPRO-Win Software for Turbine Power and Cogeneration System Design. Thermoflow Inc., Subdury, Maryland, USA.

Wang Z., Yang J., Li Z. and Xiang Y., (2009) Syngas composition study, Front. Energy Power Eng. China, 3:3, 369-372. 